\title{
Total Synthesis of Marchantinquinone
}

\section{López, E. Pandolfi and G. Seoane}

Cátedra de Química Orgánica. Facultad de Química. Universidad de la República. Gral. Flores 2124. C.C. 1157. C.P. 11800. Montevideo, Uruguay

E-mail: vlopez@bilbo.edu.uy

\begin{abstract}
During the last years, many bisbibenzylic macrocyclic ethers were isolated and identified in Hepaticae. One of them is MARCHANTINQUINONE, a quinonic macrocycle with interesting biological activity. In the following report, we present the last steps of the total synthesis.
\end{abstract}

\section{Introduction}

Bisbibenzylic systems such as Marchantins, Perrottetins, Riccardins are found only in Hepatica and have been shown to display a wide range of biological activities [1,2]. Marchantinquinone (1), from extracts of Reboulia hemisphaerica, formerly described as Mannia subpilosa, [3,4] was the first bisbibenzylic diether possessing a quinone structure isolated from Bryophytes. Herein its first synthesis is reported.

\section{Experimental}

Relevant steps of the synthesis are shown in the following retrosynthetic scheme:

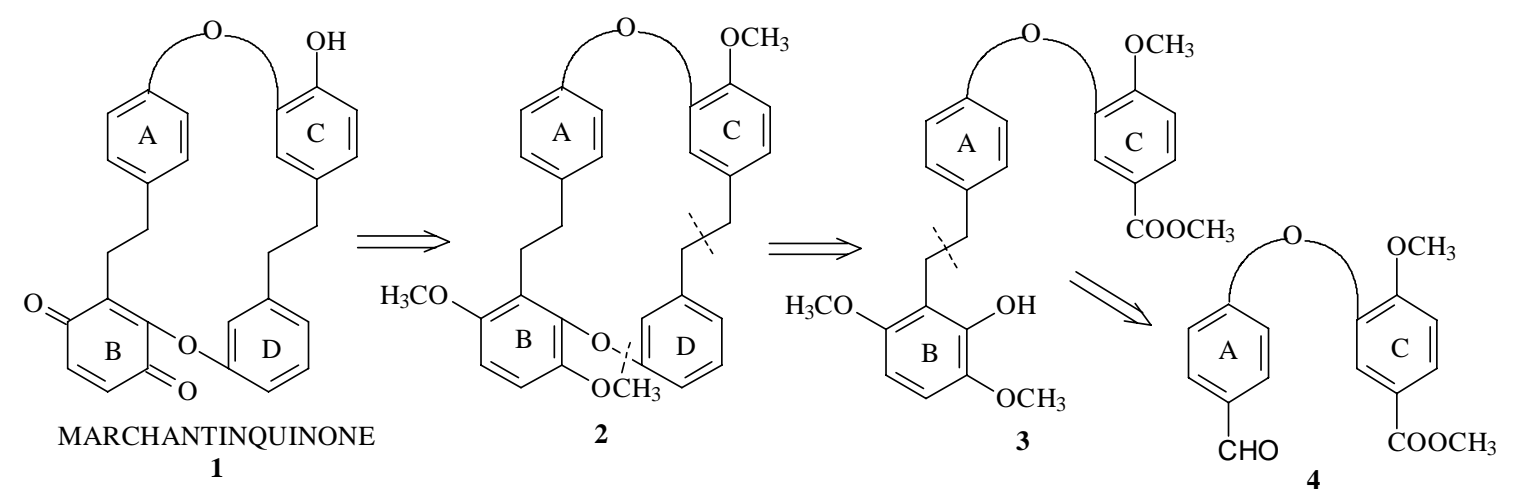

The global strategy of this synthesis is based on standard organic synthesis reactions: nucleophilic aromatic substitution, Wittig reaction, catalytic hydrogenation. It also includes redox reactions and 
macrocyclization using $\mathrm{Ni}^{\mathrm{o}}$ complex.

\section{Results and Discussion}

Previously, we described the synthesis of macrocycle (2) [5] an advance precursor of Marchantinquinone (1). Different conditions of macrocyclization, deprotection and oxidation to obtain the quinonic structure will be disclosed.

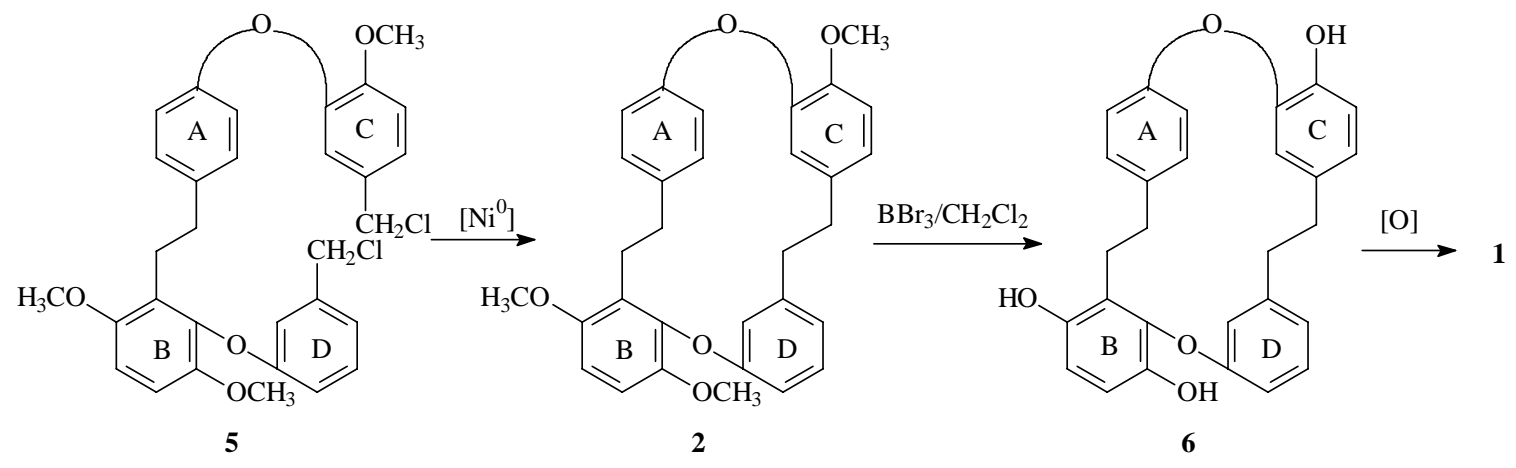

\section{References and Notes}

1. Zinsmeister, H.D.; Becker, H.; Eicher, Th. Angew. Chem. 1991, 103, 134.

2. Asakawa, Y. Progress in the Chemistry of Organic Natural Products; Herz, E.; Kirby, G.W.; Moore, R.E.; Steglick, W. C.; Tamm., Eds.; Springer: Wien, New York, 1995; p.5.

3. Wei, H.-C.; Wu, C.-L. J. Chem. Research (S) 1991, 230.

4. Wei, H.-C.; Ma, S.-J.; Wu, C.-L. Phytochemistry 1995, 39(1), 91.

5. López, V.; Pandolfi, E.; Seoane, G.; VII Jornadas de Jovens Pesquisadores do Grupo Montevideo, Curitiba, Brasil, 9-11 de setiembre de, 1999. 